\title{
Mulheres de TI em um Mundo Masculino: percepções dos homens sobre a atuação do gênero feminino no mercado de trabalho
}

\author{
Gabrieli Pereira Machado \\ Universidade Tecnológica Federal do \\ Paraná \\ Dois Vizinhos - PR, Brazil \\ gabrielimachado@alunos.utfpr.edu.br \\ Natália Tiemi Yada \\ Universidade Federal do Paraná \\ Curitiba - PR, Brazil \\ ntyada@inf.ufpr.br
}

\author{
Arielyn Pádua Silva \\ Universidade Tecnológica Federal do \\ Paraná \\ Dois Vizinhos - PR, Brazil \\ arielyn@alunos.utfpr.edu.br \\ Maynara de Oliveira Walter \\ Universidade Tecnológica Federal do \\ Paraná \\ Dois Vizinhos - PR, Brazil \\ maynarawalter@outlook.com
}

\author{
Jéssica Iara Pegorini \\ Universidade Federal do Paraná \\ Curitiba - PR, Brazil \\ jipegorini@inf.ufpr.br
}

\author{
Alinne Cristinne Correa Souza \\ Universidade Tecnológica Federal do \\ Paraná \\ Dois Vizinhos - PR, Brazil \\ alinnesouza@utfpr.edu.br
}

\begin{abstract}
Women have always fought for their place in the Information Technology area's job market. This paper presents a survey conducted with the male gender of different IT organizations from the south of Brazil. The survey aims to identify their perceptions about gender inequality, the valuing, treatment, opportunities, barriers and discrimination, and/or prejudice women suffer in the workplace. The results indicate that $45 \%$ of participants consider women in IT companies most frequently face those social barriers, and only $19 \%$ witnessed some prejudice and/or discrimination.
\end{abstract}

\section{KEYWORDS}

gender, women, labour market, infomation technology

\section{INTRODUÇÃO}

Ao longo dos anos é notável que a presença feminina na área da Tecnologia da Informação (TI) continua reduzida, o que é difícil de ser explicado, uma vez que a diferença técnica e de capacidade não explica a ausência de mulheres nesta área.

Segundo um estudo realizado entre 2013 e 2018 pela Universidade de São Paulo (USP), apenas 9\% dos alunos formados em Ciência da Computação foram do sexo feminino, $10 \%$ no curso de Bacharelado em Sistemas de Informação e apenas 6\% no curso de Engenharia da Computação. [1].

É importante destacar que assim como na graduação, no mercado de trabalho não é diferente, uma vez que a taxa de participação feminina no mercado de trabalho foi $26,5 \%$ menor que a taxa de participação masculina em 2018. Em relação ao desemprego no mesmo ano, os dados apontam que a taxa de desemprego feminino foi de $6 \%$, o que equivale a $0,8 \%$ a mais que a taxa masculina. Sendo assim, para cada dez homens que ocupam uma vaga no mercado de trabalho, apenas seis mulheres estão empregadas [2].

Embora as mulheres representem a maioria da população mundial e estejam melhor preparadas que os homens em termos de educação formal. De acordo com a pesquisa realizada pelo IBGE [3], o rendimento médio recebido pelas mulheres é predominantemente inferior ao dos homens independentemente da ocupação. Nas área de TI, essa discrepância ocorre com mais frequência, uma vez que as mulheres ainda são minoria e sofrem preconceitos e/ou discriminação em relação à suas habilidade e/ou conhecimento .

Como pode ser visto a diferença entre os gêneros é uma questão social. Apesar de homens e mulheres serem diferentes, a capacidade técnica e as competências intelectuais não são. Infelizmente essa diferença entre gêneros é imposta pela sociedade na forma como é conduzida a criação de meninos e meninas. Uma pesquisa realizada por Walter et al. [4] com 31 mulheres atuantes em diferentes áreas de TI e em diferentes empresas no sudoeste do Paraná, aponta que $29 \%$ das profissionais já sofreram alguma discriminação em algum momento e $3,2 \%$ delas relataram que na maioria das vezes sofrem discriminação ou preconceito por ser mulher.

Apesar dos constantes esforços das organizações para promover a igualdade de gêneros, na área de TI especificamente, ainda existem lacunas entre homens e mulheres no que se refere aos aspectos como representatividade, distinção no tratamento, diferença nos cargos ocupados e disparidade salarial [5]. Portanto, esta disparidade é um problema cultural que inicia muito cedo e torna-se um desafio para as mulheres tanto no ambiente acadêmico quanto no empresarial.

Neste contexto, visando identificar e analisar a percepção do público masculino sobre a atuação das mulheres de TI no mercado de trabalho no sudoeste do Paraná, um survey foi planejado e executado com homens atuantes no mercado de trabalho na área de TI. Assim, este artigo tem o intuito de apresentar o processo de planejamento e condução do survey, bem como a discussão dos resultados alcançados. Além disso, para apoiar o domínio e a disseminação da realidade das mulheres que atuam nessas organizações, serão apresentadas algumas perspectivas a respeito do cenário de desigualdade de gênero; valorização, tratamento, oportunidades, barreiras e discriminação e/ou preconceitos que as mulheres vivenciam no ambiente de trabalho.

Este artigo está organizado da seguinte forma: na Seção 2 é discutida a participação dos gêneros feminino e masculino no mercado de trabalho na área de TI. Na Seção 3 é apresentado o processo de condução do survey. Na Seção 4 são apresentados e discutidos os resultados alcançados. Por fim, na Seção 5 as considerações finais e trabalhos futuros são apresentados. 


\section{PARTICIPAÇÃO DOS GÊNEROS FEMININO E MASCULINO NO MERCADO DE TRABALHO NA ÁREA DE TI}

Nas últimas décadas estudos sobre a diferença entre os gêneros ganharam maior interesse em função das amplas transformações sociais e culturais que vem ocorrendo. Na área de TI, mais especificamente, as diferenças de oportunidades entre os gêneros ainda são significativas, o que implica nos homens ocuparem a maioria dos cargos de liderança neste setor.

Conforme a Pesquisa Nacional por Amostra de Domicílio (PNDA) do IBGE em 2018, somente $20 \%$ dos profissionais que atuam no mercado de TI são mulheres, sendo que este percentual baixo não está relacionado ao grau de educação. Segundo o IBGE [3], no Brasil, as profissionais de TI do sexo feminino têm grau de instrução mais elevado do que os homens do setor, mas, mesmo assim, ganham $34 \%$ menos do que eles. Neste contexto, segundo o estudo realizado por Correll [6] com alunos do ensino médio, algumas das razões para essas ocorrências são as "crenças culturais implantadas desde muito cedo em que a competência das mulheres em determinadas áreas é inferior à dos homens".

Apesar de tantos obstáculos e crenças, não faltam exemplos inspiradores de mulheres que desafiam os preconceitos e provam que as mulheres também tem espaço na área de TI, como por exemplo a britânica chamada Ada Lovelace. Mesmo com as diversas contribuições tecnológicas proporcionadas por mulheres, diversos trabalhos conduzidos [7], [8], [9], [5] e [10] podem afirmar que mulheres fazem parte da minoria no mercado de trabalho na área de TI, destacando a evolução da participação por gênero, a diferença na ocupação de cargos, a remuneração e a valorização por regiões.

Uma pesquisa realizada pela empresa Revelo em 2019 analisou mais de 212 mil candidatos e 27 mil ofertas de empregos empresas na plataforma a fim de realizar um comparativo entre os candidatos homens e mulheres em diferentes áreas. Como resultado a área de TI obteve $89 \%$ de candidatos masculinos e apenas $11 \%$ eram mulheres, demonstrando assim a maior tendência de homens na área de TI. A pesquisa apontou também que, independentemente da seleção da carreira ou nível do cargo dentro de uma empresa, a diferença salarial entre homens e mulheres permanecem. Na área de TI, por exemplo, as mulheres recebem cerca de $15,8 \%$ a menos do que os homens [11].

O trabalho de Batista [12] identificou e analisou o papel das políticas de diversidade de gênero de um banco,na trajetória profissional de suas gestoras. Para isso, foram entrevistados seis gestoras e seis gestores. Como resultados foi possível identificar a falta de igualdade de gênero em cargos executivos dentro do Banco, uma vez que ao serem questionados em relação às mulheres ocuparem cargos de diretoria e presidência, a grande maioria afirmou desconhecer mulheres nesses papéis.

Por fim, em [13] foi realizada uma análise das percepções sobre a desigualdade de gênero persistente no campo da Tecnologia da Informação. Essa análise buscou identificar as percepções dos homens e mulheres sobre assimetrias e diferenças em relação ao gênero, bem como compreender como homens e mulheres percebem a ausência de mulheres em cursos acadêmicos e profissionais relacionados à TI. Como resultados, foi possível identificar que as mulheres são vítimas de segregação vertical, pois com muita dificuldade atingem cargos altos tanto nas empresas como na carreira acadêmica. Além disso, muito homens expressam o seu preconceito quanto à participação do gênero feminino em trabalhos considerados "pesados" na área de TI.

Portanto, diante dos estudos apresentados, o presente artigo diferencia-se uma vez que visa realizar uma análise da percepção do gênero masculino quanto a atuação das mulheres no mercado de trabalho de TI no sudoeste do Paraná, visando identificar aspectos relacionados aos cargos ocupados, valorização, barreiras e discriminações vivenciadas por estas no ambiente de trabalho.

\section{AVALIAÇÃO EXPERIMENTAL}

Nesta seção será detalhado o survey conduzido para identificar e analisar a percepção dos homens sobre a atuação do gênero feminino em empresas de TI no sudoeste do Paraná. O survey foi planejado seguindo o processo proposto por Kasunic [14] e foram utilizados direcionamentos descritos por Kitchenham e Pfleeger [15]. Nesse sentido, o processo de condução do survey envolveu sete etapas.

\subsection{Identificação dos objetivos da investigação}

O objetivo do survey consiste na identificação da percepção do público masculino a respeito da desigualdade de gênero e da atuação das mulheres em empresas no mercado de TI no sudoeste do Paraná. Neste contexto, inicialmente procurou-se identificar os cargos ocupados pelos homens, identificar as áreas de atuação do gênero feminino, identificar a valorização do gênero feminino, detectar as barreiras que as mulheres vivenciam no ambiente de trabalho e descobrir os tipos de descriminação que as mulheres sofrem no seu ambiente de trabalho devido ao seu gênero.

Neste contexto, os objetivos do survey foram especificados de acordo com o modelo Goal-Question-Metric (GQM) proposto por Basili e Weiss [16], conforme pode ser visto na Tabela 1.

\subsection{Identificação e caracterização do público-alvo}

O público-alvo definido para participar do survey é composto por homens que estejam cursando ou sejam formados em cursos superiores na área de computação e estejam estagiando ou trabalhando em empresas na área de TI no sudoeste do Paraná. Após a definição do público-alvo, foi planejado o processo de obtenção das amostras.

\subsection{Planejamento da amostragem}

O processo de obtenção de amostras da população, foi planejado para seguir uma metodologia que oferecesse subsídios para obtenção de resultados que fossem representativos de toda a população. Nestse contexto, como estratégia para identificar diferentes perfis masculinos foi considerado localizar as empresas de TI no sudoeste do Paraná. Para obtenção de amostras da população foi realizado um contato direto com as empresas de TI que foi intercedida por alunos que trabalham nas respectivas empresas.

\subsection{Planejamento da escrita do questionário}

Nesta etapa do processo, os objetivos pré-definidos na primeira etapa (3.1) foram retificados, bem como a forma como os dados 
Table 1: Objetivos do survey

\begin{tabular}{|c|c|c|}
\hline Objetivo & Questões & Tipos de Questões \\
\hline \multirow{2}{*}{$\begin{array}{l}\text { Identificar o perfil do gênero masculino que trabal- } \\
\text { ham nas empresas de TI. }\end{array}$} & 1. Qual a faixa etária dos participantes? & Múltipla escolha. \\
\hline & $\begin{array}{l}\text { 2. Qual a situação atual em relação ao nível superior? } \\
\text { 3. Quais os cargos ocupados pelos participantes nas } \\
\text { empresas de TI? }\end{array}$ & $\begin{array}{l}\text { Múltipla escolha. } \\
\text { Questão aberta. }\end{array}$ \\
\hline $\begin{array}{l}\text { Identificar o número de mulheres atuantes em difer- } \\
\text { entes cargos nas empresas de TI. }\end{array}$ & $\begin{array}{l}\text { 1. Qual o número de mulheres que trabalham nas em- } \\
\text { presas de TI? } \\
\text { 2. Quais os cargos ocupados pelas mulheres que tra- } \\
\text { balham nas empresas de TI? }\end{array}$ & $\begin{array}{l}\text { Questão aberta com somente } \\
\text { números. } \\
\text { Questão aberta. }\end{array}$ \\
\hline \multirow{2}{*}{$\begin{array}{l}\text { Identificar, a partir das percepções do gênero mas- } \\
\text { culino, a valorização das mulheres nas empresas de } \\
\text { TI. }\end{array}$} & $\begin{array}{l}\text { 1. Quão valorizadas são as mulheres que trabalham } \\
\text { nas empresas de TI? }\end{array}$ & Escala Likert. \\
\hline & $\begin{array}{l}\text { 2. Existe distinção na forma como as mulheres são } \\
\text { tratadas em relação ao homens na área de TI? }\end{array}$ & Escala Likert. \\
\hline \multirow{2}{*}{$\begin{array}{l}\text { Detectar, a partir das percepções do gênero mas- } \\
\text { culino, as oportunidades e barreiras enfrentas pelas } \\
\text { mulheres nas empresas de TI. }\end{array}$} & $\begin{array}{l}\text { 1. Quais são os principais desafios enfrentados pelas } \\
\text { mulheres nas empresas de TI? }\end{array}$ & Múltipla escolha. \\
\hline & $\begin{array}{l}\text { 2. O gênero feminino possui as mesmas oportu- } \\
\text { nidades que o gênero masculino nas empresas de TI? }\end{array}$ & Escala Likert. \\
\hline \multirow{2}{*}{$\begin{array}{l}\text { Descobrir, a partir das percepções do gênero mas- } \\
\text { culino, discriminações vivenciadas pelas mulheres } \\
\text { nas empresas de TI. }\end{array}$} & $\begin{array}{l}\text { 1. É confortável ser liderado/gerenciado por uma } \\
\text { mulher? }\end{array}$ & Múltipla escolha. \\
\hline & $\begin{array}{l}\text { 2. Quais são os tipos de descriminações vivenciadas } \\
\text { pelas mulheres nas empresas de TI? }\end{array}$ & Questão aberta. \\
\hline
\end{tabular}

das participantes seriam coletados. Considerando que não ocorreu contato presencial com as participantes, foi definido que o survey seria disponibilizado em formato de questionário eletrônico.

O questionário eletrônico foi desenvolvido utilizando a ferramenta Google Forms ${ }^{1}$. As questões foram estruturadas em três seções. A primeira seção contém uma apresentação do survey em que é descrito o objetivo do mesmo e o público-alvo. A segunda seção foi desenvolvida para coletar informações que caracterizam os participantes. Por fim, a última seção teve a finalidade de coletar informações a respeito do comportamento e percepções dos homens sobre o gênero feminino relacionadas à quantidade de mulheres que atuam próximas e seus respectivos cargos, valorização, tratamento, oportunidades, barreiras, possíveis preconceitos e/ou discriminações que tenham presenciado.

Após o desenvolvimento do questionário eletrônico, foi realizada uma execução piloto, visando analisar a validade do instrumento.

\subsection{Execução do piloto}

Segundo Kasunic [14] conduzir um survey piloto é fundamental, pois permite detectar possíveis problemas existentes no mesmo. Uma forma de verificar a validade de um instrumento é por meio da avaliação do seu conteúdo. Para avaliar o survey foram utilizadas quatro questões abertas propostas por Hauck et al. [17], que são: (1) O questionário contém tudo que é esperado para contemplar o seu objetivo?; (2) O questionário contém quaisquer informações não desejáveis ou desnecessárias ao contexto e objetivo da pesquisa?; (3) Você conseguiu compreender adequadamente as perguntas?; e (4) Existe algum erro ou inconsistência no questionário?

\footnotetext{
${ }^{1}$ Mais informações podem ser obtidas em: <https://www.google.com/forms/about/>
}

Neste contexto, um grupo de quatro participantes distribuídos entre formados e não formados, estagiando e trabalhando foram convidados por e-mail para participar do survey piloto. Estes participantes, foram selecionados pelos critérios de disponibilidade, participaram do estudo piloto respondendo as questões propostas por Hauck et. al [17].

Após a execução do survey piloto, os participantes avaliaram e enviaram seus feedbacks. A avaliação dos participantes foi positiva, com sugestões para: (i) reduzir o número de perguntas; (ii) deixar algumas perguntas como não obrigatórias; e (iii) incluir uma pergunta aberta.

\section{DISCUSSÃO E ANÁLISE DOS RESULTADOS}

O survey obteve a contribuição de 64 participantes, sendo eles homens atuantes em diferentes áreas de TI de diferentes organizações, que abrangem as cidades do sudoeste do Paraná. Os resultados serão apresentados de acordo com os objetivos apresentados na Tabela 1 na Seção 3.1.

\subsection{Perfil do gênero masculino nas empresas de TI}

As perguntas relacionadas ao perfil do gênero masculino visam apresentar as informações gerais dos participantes. Neste contexto, a Figura 1 representa a faixa etária de todos os participantes, na qual observa-se que o maior percentual está na faixa etária de até 21 anos, o que equivale à $31,3 \%(20 / 64)$ dos participantes. Os demais se encaixam nas faixa etárias de 22 a 25 e 26 a 30 anos, representando respectivamente $23,4 \%(15 / 64)$ e $29,7 \%$ (19/64); e somente $15,6 \%$ (10/64) dos participantes possuem mais de 30 anos de idade. 


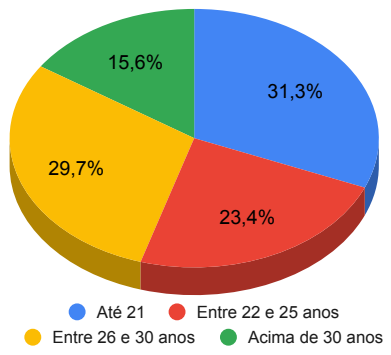

Figure 1: Percentual da faixa etária dos participantes

Para apoiar a caracterização do gênero masculino, foi solicitado aos participantes que informassem se já são formados ou estão cursando algum curso superior. A partir dessas informações foi possível observar que 51,6\% (33/64) dos participantes já estão formados e 48,4\% (31/64) ainda estão cursando a graduação.

Além disso, foi possível identificar que o maior índice de participantes formados está na faixa etária de 26 a 30 anos, o que representa $52 \%$ (17/33) do total de formados, conforme pode ser visto na Figura 2. Por outro lado, 61\% (19/31) dos participantes que ainda estão cursando a graduação encontram-se na faixa etária de até 21 anos e 29\% (9/31) na faixa de 22 a 25 anos de idade.

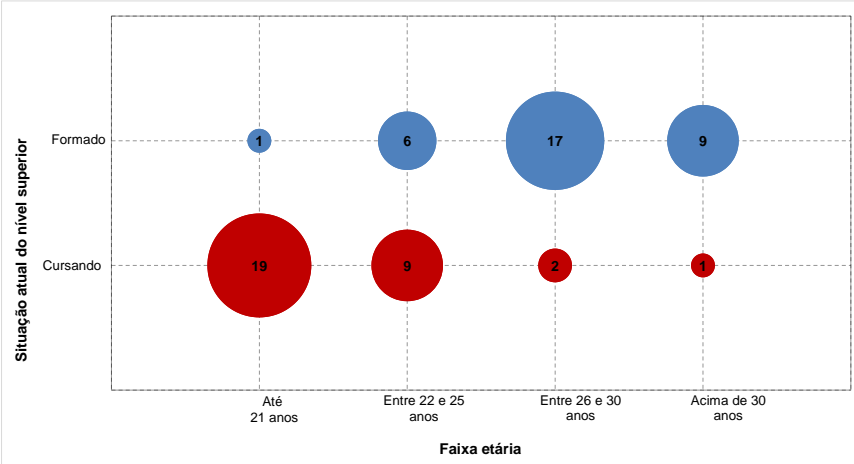

Figure 2: Distribuição dos participantes formados e cursando a graduação de acordo com a faixa etária

Os participantes também responderam sobre suas respectivas formações, no qual os cursos de Engenharia de Software e Sistemas da Informação são os que mais se destacaram, aparecendo em $44 \%$ $(28 / 64)$ e $34 \%$ (22/64) das respostas respectivamente. Outros cursos de graduação, como Análise e Desenvolvimento de Sistemas, Tecnologia de Sistemas para Internet também foram mencionados nas respostas.

Foi definida uma questão buscando identificar se atualmente os participantes estão trabalhando ou estão em período de estágio, na qual 90,6\% (58/64) deles alegaram que estão trabalhando, enquanto os demais 9,4\% (6/64) estão estagiando na área de TI.

Por meio dos resultados alcançados, pode-se observar que $82,3 \%$ (53/64) do gênero masculino não possui dificuldades de ingressar no mercado de trabalho. Este mesmo cenário também acontece para o gênero feminino, o qual foi constatado no estudo de Walter et al.
[4] que $71 \%$ das mulheres não tiveram dificuldades para encontrar trabalho na área.

Por fim, para a facilitar a organização dos dados referentes aos cargos ocupados pelos participantes, os mesmos foram agrupados em oito categorias diferentes conforme são apresentados na Tabela 2. É importante destacar que a categoria " $C_{8}$ - Outros" contempla os cargos que não estão diretamente relacionados à área de TI.

Table 2: Categorização dos cargos ocupados pelos participantes nas empresas de TI

\begin{tabular}{|c|c|}
\hline Categorias & Cargos \\
\hline $\mathrm{C}_{1}$ - Analista & Requisitos, Negócio, Sistemas ERP. \\
\hline $\mathrm{C}_{2}$ - Desenvolvedor & $\begin{array}{l}\text { Desenvolvedor pleno, fullStack, powee- } \\
\text { builder, programador, c++, front-end, back- } \\
\text { end, android, desenvolvedor. }\end{array}$ \\
\hline $\mathrm{C}_{3}$ - Designer & Product design, UX designer. \\
\hline $\mathrm{C}_{4}$ - Gerência & $\mathrm{CEO}^{2}$, líder técnico, gestor, coordenador. \\
\hline $\mathrm{C}_{5}$ - Suporte & $\begin{array}{l}\text { Analista de suporte ERP, suporte técnico, } \\
\text { analista de implantação, analista de config- } \\
\text { uração, analista pós implantação. }\end{array}$ \\
\hline $\mathrm{C}_{6}$ - Testador & Automatizador de teste, testador. \\
\hline $\mathrm{C}_{7}$ - Trainee & Estagiário, trainee. \\
\hline $\mathrm{C}_{8}$ - Outros & $\begin{array}{l}\text { Representante da equipe de vendas (SDR), } \\
\text { analista de atendimento de sistemas, anal- } \\
\text { ista contábil fiscal }\end{array}$ \\
\hline
\end{tabular}

A Figura 3 apresenta a distribuição dos 30 cargos diferentes, apresentados na Tabela 2, agrupados nas suas respectivas categorias. Por meio da análise dos resultados, é possível destacar que 51,6\% (33/64) do total de participantes ocupam cargos referentes a categoria $C_{2}$. Em segundo lugar, a categoria mais ocupada pelos participantes é a $C_{4}$ que representa $12,5 \%(8 / 64)$. Por fim, as categorias menos ocupadas pelos participantes são $C_{3}$ e $C_{7}$, ambas com $3,1 \%(2 / 64)$ dos participantes.

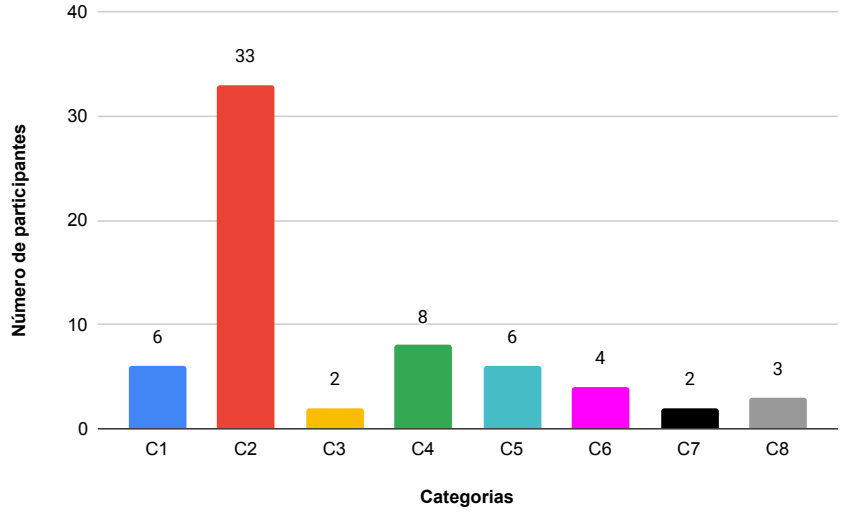

Figure 3: Cargos ocupados pelos participantes nas empresas de TI 


\subsection{Cargos ocupados pelas mulheres nas empresas de TI}

Visando identificar o panorama geral das mulheres na área de TI nas empresas, foi solicitado aos participantes que indicassem o número de mulheres que trabalham nessa área em suas respectivas empresas, bem como seus cargos.

Neste contexto, a Figura 4 apresenta o número de mulheres que trabalham diretamente com os participantes, na qual 54,7\% (35/64) dos participantes responderam que "entre 1 e 4 mulheres" trabalham diretamente com ele. Apenas 1,6\% (1/64) dos participantes responderam "entre 11 e 15 mulheres" e 3,1\% (2/64) "mais de 15 mulheres".

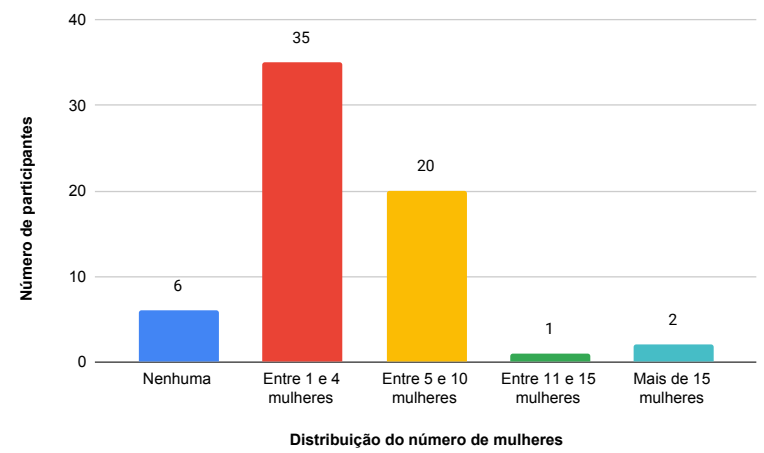

Figure 4: Número de mulheres que trabalham diretamente com o participante na área de TI

Por meio desses dados coletados, pode-se observar que mesmo que as mulheres venham conquistando o seu espaço nos mais diferentes cargos e profissões, a carência do gênero feminino na área do TI ainda é consideravelmente alto, levando em conta que dos 64 participantes, apenas três disseram trabalhar com até 15 ou mais mulheres. A ausência de mulheres nessa área pode ser observada por meio das respostas dos outros 61 participantes, que relataram trabalhar com poucas mulheres em seus referidos setores.

Visando facilitar a distribuição dos cargos ocupados pelo gênero feminino nas empresas de TI que os participantes trabalham, os mesmos foram agrupados em cinco categorias conforme é ilustrado na Tabela 3. De acordo com essa categorização, a Tabela 4 apresenta os resultados sobre os diferentes tipos de cargos ocupados pelas mulheres próximas aos participantes dentro das empresas de TI.

Conforme pode ser observado na Tabela 4, independente do tipo de cargo, a maioria dos participantes não trabalha com "nenhuma" mulher diretamente ou identificou na empresa que somente "entre 1 e 4 mulheres" estão trabalhando próximas. Além disso, é notável que os cargos pertencentes as categorias $C_{3}$ e $C_{2}$ são os mais ocupados pelas mulheres nas empresas dos participantes. 59\% (38/64) e 37\% (24/64) dos participantes mencionaram que "entre 1 e 4 mulheres" estão trabalhando como desenvolvedora/testadora $\mathrm{e}$ analista, respectivamente. No entanto, os cargos com menor presença do gênero feminino, são aqueles das categorias $C_{1}$ e $C_{5}$, uma vez que $86 \%$ (55/64) e 83\% (53/64) dos participantes afirmaram não conhecer nenhuma mulher trabalhando em ambos os cargos dentro das empresas.
Table 3: Categorização dos cargos ocupados pelas mulheres nas empresas de TI que os participantes trabalham

\begin{tabular}{|c|c|}
\hline Categorias & Cargos \\
\hline $\begin{array}{l}\mathrm{C}_{1} \quad-\quad \text { Admin- } \\
\text { istradora de Banco } \\
\text { de Dados }\end{array}$ & $\begin{array}{l}\text { Analista, administradora ou auxiliar de } \\
\text { banco de dados. }\end{array}$ \\
\hline $\begin{array}{l}\mathrm{C}_{2} \text { - Analista e De- } \\
\text { signer }\end{array}$ & $\begin{array}{l}\text { Analista de requisitos, analista de negócios, } \\
\text { designer, designer } U X \text {, designer de produto. }\end{array}$ \\
\hline $\begin{array}{l}\mathrm{C}_{3} \text { - Desenvolve- } \\
\text { dora e testadora }\end{array}$ & $\begin{array}{l}\text { Desenvolvedora e testadora web, mobile, } \\
\text { desktop. }\end{array}$ \\
\hline $\mathrm{C}_{4}$ - Gerência & $\begin{array}{l}\text { CEO, scrum master, líder técnico, gestora, } \\
\text { gerente, coordenadora. }\end{array}$ \\
\hline $\mathrm{C}_{5}$ - Suporte & $\begin{array}{l}\text { Redes, suporte, sistema operacional, implan- } \\
\text { tação de sistemas, configuração de sistemas. }\end{array}$ \\
\hline
\end{tabular}

Seguindo ainda nesta linha, foi solicitado aos participantes que identificassem se além das mulheres que trabalham em suas empresas, eles conheciam outras mulheres que trabalhassem em cargos de gerência. Na Figura 5 é possível observar que 52\% (33/64) dos participantes afirmaram conhecer "entre 1 e 4 mulheres" ocupando esse tipo de cargo. Por outro lado, $22 \%$ (14/64) dos participantes afirmaram não conhecer nenhuma mulher ocupando o cargo de liderança. Esses percentuais indicam que mesmo de uma forma tímida existem mulheres em cargos de liderança.

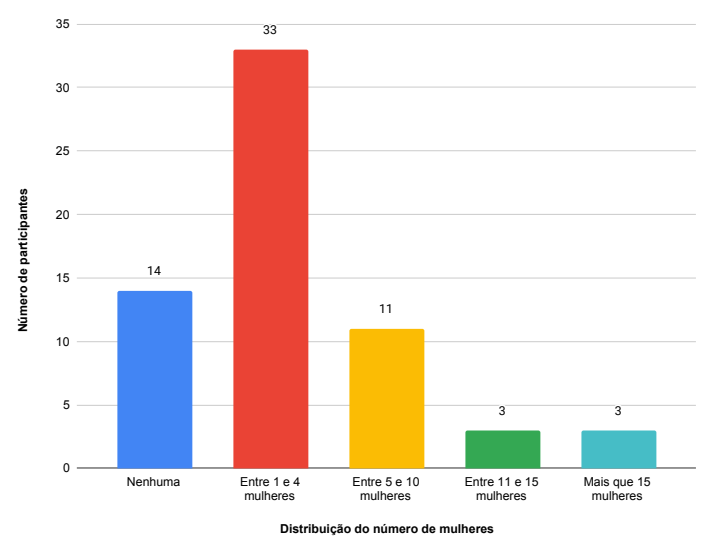

Figure 5: Número de mulheres conhecidas pelos participantes que assumem cargos de liderança em outras empresas de TI

\subsection{Valorização das mulheres nas empresas de TI}

Com o propósito de identificar a valorização do gênero feminino nas empresas de TI, foi solicitados aos participantes que identificassem o quanto as mulheres são valorizadas e se recebem o mesmo tratamento que o gênero masculino.

Para facilitar a análise dos resultados coletados foi utilizada a escala Likert. O formato de resposta para os itens da escala é baseado em 5 pontos, variando de: (5) Sempre, (4) Na maioria das vezes, (3) 
Table 4: Nível de conhecimento dos participantes quanto aos cargos ocupados pelas mulheres nas empresas de TI que trabalham

\begin{tabular}{|c|c|c|c|c|c|c|}
\hline \multirow{2}{*}{$2 *$ Categorias } & \multicolumn{6}{|c|}{ Nível de conhecimento dos participantes sobre a distribuição do número de mulheres } \\
\hline & Nenhuma & $\begin{array}{l}\text { Entre } 1 \text { e } 4 \\
\text { mulheres }\end{array}$ & $\begin{array}{l}\text { Entre } 5 \text { e } 10 \\
\text { mulheres }\end{array}$ & $\begin{array}{l}\text { Entre } 11 \text { e } 15 \\
\text { mulheres }\end{array}$ & $\begin{array}{l}\text { Mais de } 15 \\
\text { mulheres }\end{array}$ & Não sei \\
\hline $\mathrm{C}_{1}$ - Administradora de Banco de Dados & 55 & 4 & 0 & 1 & 0 & 4 \\
\hline $\mathrm{C}_{2}$ - Analista e Designer & 32 & 24 & 4 & 1 & 0 & 3 \\
\hline $\mathrm{C}_{3}$ - Desenvolvedora e Testadora & 16 & 38 & 6 & 1 & 1 & 2 \\
\hline $\mathrm{C}_{4}$ - Gerência & 30 & 30 & 0 & 1 & 0 & 3 \\
\hline $\mathrm{C}_{5}$ - Suporte & 53 & 4 & 3 & 0 & 1 & 3 \\
\hline
\end{tabular}

Ás vezes, (2) Raramente até (1) Nunca. A Figura 6 apresenta os resultados referente à valorização e tratamento das mulheres no seu ambiente de trabalho.

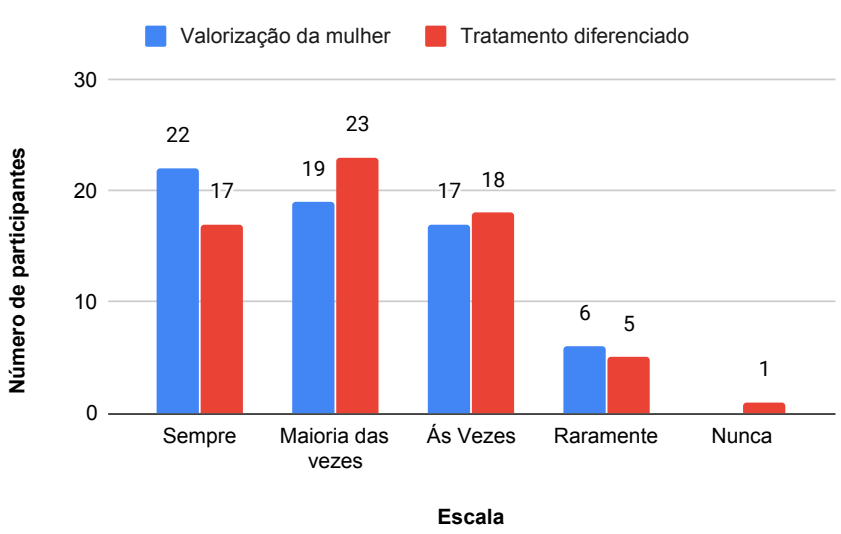

Figure 6: Valorização e tratamento dedicados ao gênero feminino nas empresas de TI

No que diz respeito a valorização do gênero feminino no ambiente de trabalho, 34\% (22/64) dos participantes afirmaram que as mulheres "sempre" são valorizadas, enquanto somente 9\% (6/64) acham que "raramente" elas são valorizadas. A mesma percepção pode ser observada quanto ao tratamento dedicado às mulheres por parte de colegas, clientes, entre outros, no qual 27\% (17/64) dos participantes acham que "sempre" o tratamento dedicado ao gênero feminino é similar ao dedicado ao gênero masculino. Por outro lado, $8 \%$ (5/64) acham que "raramente" esse tratamento é o mesmo.

\subsection{Oportunidades e barreiras enfrentadas pelas mulheres nas empresas de TI}

Para identificar os desafios das mulheres nas empresas de TI, foi solicitado aos participantes que apresentassem suas percepções quanto as barreiras enfrentadas pelo gênero feminino, e se as mulheres possuem as mesmas oportunidades que o gênero masculino. A Figura 7 apresenta os resultados para esse objetivo do survey, utilizando a mesma escala apresentada na Seção 4.3.

Quando questionados sobre as oportunidades oferecidas ao gênero feminino dentro das empresas de TI, 33\% (21/64) dos participantes responderam que na "maioria das vezes" as mulheres têm as mesmas

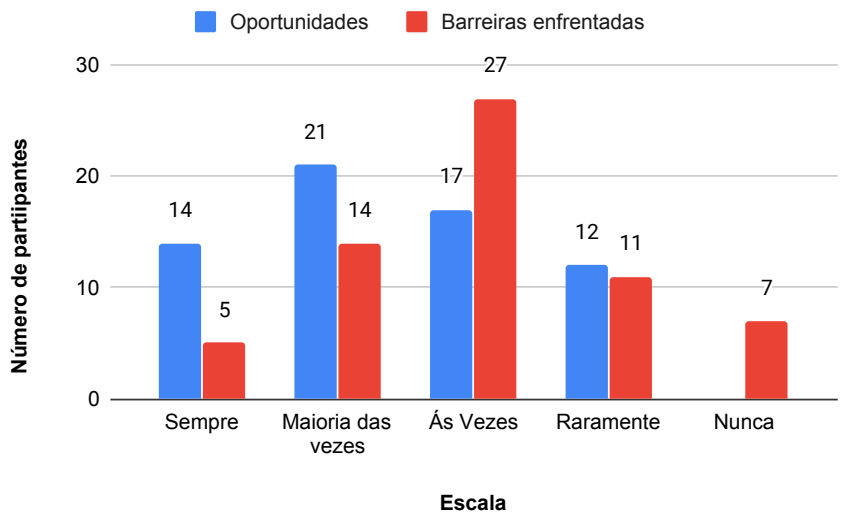

Figure 7: Oportunidades de trabalho e barreiras enfrentadas pelo gênero feminino nas empresas de TI

oportunidades que os homens, enquanto que 19\% (12/64) opinaram que "raramente" isso acontece.

Em relação às barreiras enfrentadas pelas mulheres nessas empresas, $11 \%$ (7/64) dos participantes responderam que não existe nenhum tipo de barreira, enquanto $42 \%$ (27/64) dizem que "às vezes" as barreiras podem existir. Neste contexto, para identificar a percepção dos homens quanto aos tipos de barreiras enfrentadas pelas mulheres, as mesmas foram divididas em quatro categorias: (i)Social: está relacionada à desigualdade dos gêneros; (ii) Técnica: está relacionada ao conhecimento técnico envolvido na área/cargo ocupado; (iii) Social e Técnica: contempla as duas barreiras mencionadas acima; e (iv) Nenhuma das opções: está relacionado à outros tipos de barreiras.

Conforme pode ser visto na Figura 8, 45,3\% (29/64) dos participantes consideram que a barreira social é enfrentada com mais frequência pelas mulheres nas empresas de TI. Enquanto que 21,9\% $(14 / 64)$ dos participantes acredita que somente a barreira técnica é enfrentada pelas mulheres, ou seja, que as dificuldades advém da falta de conhecimento. Por fim, 14,1\% (9/64) dos participantes responderam que nenhuma dessas barreiras são enfrentadas pelas mulheres.

Com esses resultados é possível constatar que as mulheres ainda sofrem com a desigualdade de gêneros, principalmente por estarem atuando em uma área com maior índice do gênero masculino, uma vez que que a maioria dos participantes acredita que a barreira 


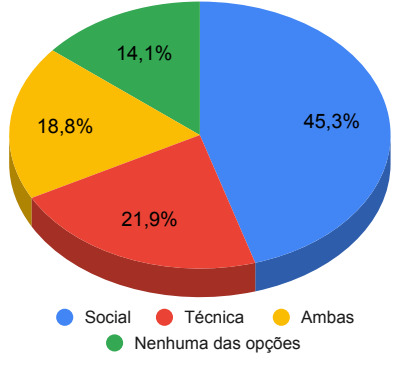

Figure 8: Barreiras vivenciadas pelo gênero feminino no ambiente de trabalho

social é um dos principais desafios enfrentados pelas mulheres no ambiente de trabalho.

\subsection{Discriminações vivenciadas pelas mulheres nas empresas de TI}

Por fim, o último objetivo do survey buscou investigar se os participantes se sentem confortáveis em serem liderados por uma mulher e se presenciaram algum tipo de assédio, preconceitos e/ou brincadeiras que as mulheres possam ter sofrido no ambiente de trabalho.

Quando questionados a respeito da liderança feminina nas empresas, 98\% (63/64) dos participantes se mostraram favoráveis a serem liderados por mulheres. No entanto, um participante relatou que não se sente confortável com este cenário, justificando que: "Mulher em cargo de poder não da certo. São mais influenciáveis que os homens. E quando contrariadas costumam ser vingativas e levar tudo para o lado pessoal". Este tipo de comentário constata o resultado apresentado em relação a barreira social na Figura 8.

Embora a maioria dos participantes não veja problemas em serem liderados por uma mulher, o preconceito ligado ao gênero feminino ainda é um grande desafio a ser enfrentado pelas mulheres nas empresas. O maior deles com certeza está em ocupar um cargo de liderança visto que a visão tradicional de um líder está muito ligada ao gênero masculino [18]. Neste contexto, segundo Hryniewicz et. al [19] a dificuldade que o gênero feminino encontra para ocupar um cargo de líder está relacionada a diversos fatores como: pressão, autoconfiança, ofensas pessoais, assédio, falta de receptividade e diversos desafios ao liderar o gênero masculino. Esses fatores se agravam principalmente quando existe a presença de homens mais velhos, pois em determinadas situações é necessário que a mulher fale mais alto para ser ouvida, porém a mesma pode ser mal interpretada.

Por fim, buscou-se descobrir junto aos participantes suas percepções quanto às discriminações vivenciadas pelas mulheres nas empresas de TI. Para facilitar a discussão dos resultados, os relatos dos participantes foram agrupados em três categorias:

- " $C_{1}$ - Brincadeiras inadequadas": contempla comportamentos relacionados a brincadeiras ofensivas e apelidos;

- " $C_{2}$ - Discriminação": agrupa comportamentos relacionados à comentários que remetem à posição de inferioridade $\mathrm{e}$ atitudes hostis;
- " $C_{3}$ - Assédio": aborda comportamentos que incomodam, importunam, humilham ou perseguem uma mulher no seu ambiente de trabalho.

Na Figura 9 é possível observar relações de união e intersecção entre os comportamentos, agrupados nas categorias, presenciados pelos participantes.

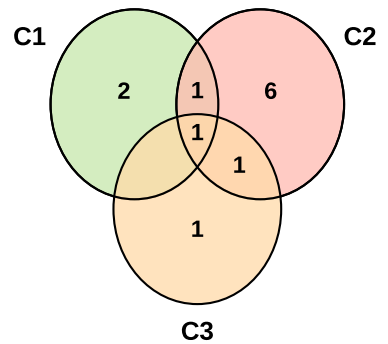

Figure 9: Brincadeiras, discriminação e assédio presenciados pelos participantes nas empresas de TI em que trabalham

É possível observar que somente 19\% (12/64) do total dos participantes relataram que presenciaram algum desses tipos de comportamentos. Participantes que presenciaram colegas de trabalho do gênero feminino sofrerem algum tipo de brincadeira inadequada no ambiente de trabalho $\left(C_{1}\right)$ representam um percentual de $3,1 \%$ $(1 / 64)$ do total dos participantes. Já, os casos de discriminação $\left(C_{2}\right)$, foram presenciados por 9,4\% (6/64) dos participantes.

Além disso, é importante destacar que na união das três categorias apresentadas na Figura 9, é possível observar que dos 12 participantes, somente um presenciou os três tipos de comportamentos (agrupados em " $C_{1}$ ", " $C_{2} e$ " $C_{3}$ ) com colegas de trabalho do gênero feminino. Essa percepção é possível relacionar aos resultados apresentados na Figura 8, confirmando que a barreira social é a mais enfrentada pelo gênero feminino no ambiente de trabalho.

Neste contexto, dentre as 12 percepções dos participantes, um deles relatou um episodio de "Líder pegando na perna de uma menina da sua equipe (que na época tinha menos de 18), e fazendo piada de que não sabe nem o que faria com ela". O porte adotado pelo líder em questão, demonstra muito sobre o abuso de autoridade, e principalmente o assédio cometido contra a mulher.

Um participante comentou que "Uma colega recebeu um apelido inapropriado" que está diretamente relacionado com a categoria " $C_{1}$ - Brincadeiras inadequadas". Outro participante relatou que " $\mathrm{Na}$ empresa anterior sempre haviam comentários do tipo tinha que ser mulher". Esse tipo de comportamento enfatiza os resultados identificados quanto às barreiras técnicas. Portanto, os comentários apresentados indicam que somente $19 \%$ dos participantes veem as mulheres como seres inferiores como senão tivessem capacidade e/ou habilidades de realizar as mesmas tarefas ou tomar decisões.

Ao final do survey, os participantes puderam expressar suas opiniões sobre programas que visam incentivar a inserção de mulheres na área de TI de forma igualitária. Para facilitar a compreensão dos resultados, todos os comentários foram categorizados em: (i) opiniões favoráveis; (ii) opiniões neutras; (iii) opiniões desfavoráveis; e (iv) nenhuma opinião. 
Do total de participantes, 94\% (60/64) deixaram comentários e opiniões diversificadas sobre o assunto. 63\% (40/64) deles se mostram favoráveis e apoiadores desses programas, como por exemplo "Na minha opinião é importante sempre incentivar as pessoas a não se aprisionar a opinião imposta pela sociedade, pois essa é a pior escravidão que existe no mundo. Por outro lado $22 \%(14 / 64)$ se mantiveram neutros, sem ter uma opinião formada sobre o assunto ou comentando que "não é o sexo que define a capacidade do profissional". Por fim, somente 9\% (6/64) deles não se mostraram favoráveis a esses tipos de programas, comentando que "são programas desnecessários" e, 6\% (4/64) não opinaram.

Portanto, a partir dos feedbacks dos participantes, pode-se notar que existem muitos homens que apoiam a inserção das mulheres, não só em empresas de TI, como em todas as demais áreas. Alguns resultados indicaram que a ausência do gênero feminino em empresas de TI se trata também de afinidade. Outros resultados apontaram que não é o sexo do profissional que importa para as empresas, e sim a capacidade que o mesmo possui para desempenhar o seu trabalho e obter bons resultados. Mesmo que a área de TI ainda seja uma das que mais possui deficit do gênero feminino, os resultados revelaram um grande número de entusiastas de programas que visam incentivar o aumento da participação mulheres nesta área.

\section{CONSIDERAÇÕES FINAIS}

Este artigo apresentou o planejamento, a execução e os resultados da execução de um survey visando identificar a percepção do gênero masculino sobre as mulheres que atuam na área de TI no mercado de trabalho. Para isso, foi realizada uma coleta e análise com homens que atuam nessa área em empresas no sudoeste do Paraná, buscando compreender suas percepções em relação a esse cenário de desigualdade.

O processo de Kasunic [14] para construção do survey e alguns direcionamento de Hauck et al. [17] foram utilizados. Visando auxiliar a definição dos objetivos, foi utilizada a abordagem GQM proposta por Basili e Weiss [16]. Com objetivo de mitigar as possíveis ameaças a validade da pesquisa, foi conduzido um survey piloto com quatro participantes. Com os resultados dessa execução e feedback dos participantes, foram realizadas revisões e melhorias em relação ao formato e quanto à formulação de perguntas.

Outra possível ameaça deste estudo está relacionada ao fato dos resultados do survey serem provenientes de respostas subjetivas dos participantes. Neste contexto, é possível que essas respostas não representem a verdadeira percepção dos participantes sobre a participação do gênero feminino na área de TI. O número limitado de participantes do survey também pode ser considerada uma ameaça à validade. Apesar do conjunto de respostas serem satisfatórios, seria importante ter uma maior contribuição de participantes de todas as regiões do Brasil.

Como os resultados, é possível notar ainda a carência de mulheres atuando na área de TI, o que reduz suas chances de assumirem cargos altos nas organizações. Neste contexto, $45 \%$ dos participantes consideram que as barreiras sociais são mais frequentemente enfrentadas pelas mulheres nas empresas de TI, contrastando os resultados apresentados no estudo de Walter et al. [4], no qual 54,8\% (17/31) das participantes se sentem ou já se sentiram prejudicadas no seu ambiente de trabalho pelo fato de ser mulher.
Os resultados também demonstram que apenas 19\% dos participantes testemunharam algum tipo de discriminação, brincadeiras inadequadas e/ou assédio. Portanto, conforme foi relatado pelos participantes, é notório que o desafio para alcançar uma igualdade de gênero na área de TI é contínuo e, que ainda existe preconceito em relação ao público feminino dominar conhecimentos nessa área.

A partir da apresentação do survey neste artigo, como novas perspectivas de pesquisas futuras espera-se: (i) realizar essa pesquisa contemplando outras regiões do Sul; (ii) analisar a relação, as similaridades e as diferenças da atuação do público feminino e masculino na academia e na indústria na área de TI; e (iii) analisar a situação das mulheres negras, homossexuais ou com necessidades especiais na área de TI.

\section{REFERENCES}

[1] Carolina Martins Santos. Por que as mulheres "desapareceram" dos cursos de computação?, 2018. URL https://jornal.usp.br/universidade/por-que-as-mulheresdesapareceram-dos-cursos-de-computacao/. Acessado em : 02 mai. 2020.

[2] OIT. Perspectivas sociales y del empleo en el mundo: Avance gloabal sobre las tendencias del empleo femenino, 2018. URL https://www.ilo.org/global/research/global-reports/weso/trends-forwomen2018/WCMS_619603/lang--es/index.htm. Acessado em : 20 ago. 2020.

[3] IBGE. Mercado de trabalho brasileiro, 2018. URL https://agenciadenoticias.ibge. gov.br/agencia-sala-de-imprensa/2013-agencia-de-noticias/releases/23923-em2018-mulher-recebia-79-5-do-rendimento-do-homem. Acessado em : 20 ago. 2020.

[4] M. O. Walter, N. T. Yada, J. I. Pegorini, A. P. Silva, and A. C. C. Souza. We can do it: Uma análise do perfil feminino de computação no mercado de trabalho. In Proceedings of the XI Computer on the Beach, pages 1-10, 2020.

[5] A. Cardoso and D. M. M. Hanashiro. Percepção masculina sobre as barreiras das mulheres executivas. Revista PRETEXTO, 19(1):73-89, 2018.

[6] S. J. CORRELL. Gender and the career choice process: The role of biased selfassessments. American fournal of Sociology, 106(6):1691-1730, 2011

[7] E. K Kelan. Gender fatigue: The ideological dilemma of gender neutrality and discrimination in organizations. Canadian fournal of Administrative Sciences, 26 (3):197-210, 2009.

[8] J. H. Nunes. Gênero e raça no trabalho em tecnologia da informação (ti). Ciências Sociais Unisinos, 52(3):383-395, 2016

[9] J. J. Souza. Mulheres na TI: Análise da Inserção e Situação das Mulheres da Área de Tecnologia da Informação na Grande Florianópolis. Monografia, Universidade do Sul de Santa Catarina (UNISUL), Palhoça, SC, 2017.

[10] Ana Paula Meneghetti. Gap de gênero, 2019. URL https://www.istoedinheiro. com.br/gap-de-genero/. Acessado em : 20 ago. 2020.

[11] Carlos. Estudo retrata a desigualdade de gênero em tecnologia, 2019. URL https://radardofuturo.com.br/estudo-retrata-a-desigualdade-de-genero-emtecnologia/. Acessado em : 20 ago. 2020.

[12] Gabrielle Rodrigues Batista. Gestão feminina em instituição financeira : igualdade de gênero, discurso $x$ realidade. Trabalhos de conclusão de curso, Universidade Federal do Rio Grande do Sul (UFRGS), Porto Alegre, RS, Brasil, 2018.

[13] P. A. S. V. Felisberto. TIC e as Desigualdades de Género: Reprodução Social e Mudança nos Percursos Profissionais. Dissertação de mestrado, Universidade da Beira Interior, Covilhã, Portugal, Outubro 2012

[14] Mark Kasunic. Designing an effective survey. Pittsburgh: Carnegie Mellon University, 2005

[15] Kitchenham B. A. and S. L. Pfleeger. Guide to advanced empirical software engineering. chapter Personal opinion surveys., pages 63-92. Springer London, London, 2008.

[16] V. Basili and D. Weiss. A methodology for collecting valid software engineering data. IEEE Transactions on Software Engineering, 10(6):728-738, 1984.

[17] J. C. R. Hauck, C. G. Von Wangenheim, and A. Von Wangenheim. Método de aquisição de conhecimento para customização de modelos de capacidade/maturidade de processos de software. Relatório técnico, INCoD, Florianópolis, SC, 2011.

[18] Alice H. Eagly. Female leadership advantage and disavantage: Resolving the contradictions. Psychology of Women Quarterly, 31(1):1-12, 2007. doi: 10.1111/j. 1471-6402.2007.00326.x.

[19] Lygia Goncalves Costa Hryniewicz and Maria Amorim Vianna. Mulheres em posição de liderança: Obstáculos e expectativas de gênero em cargos gerenciais. Cadernos EBAPE.BR, 16:331-344, 09 2018. ISSN 1679-3951. 